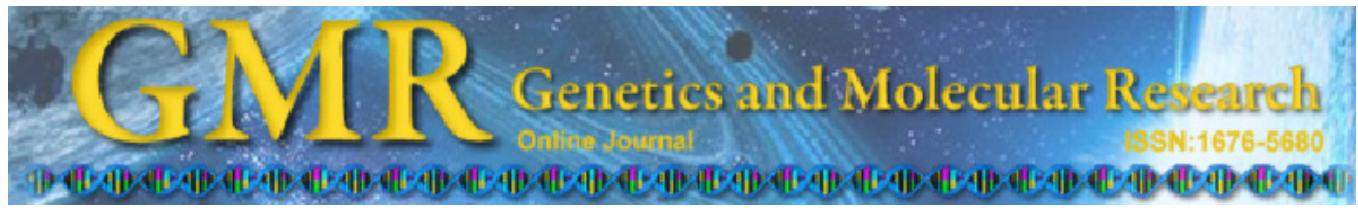

\title{
Expressed sequence tag-simple sequence repeat-based molecular variance in two Salicornia (Amaranthaceae) populations
}

\author{
Z.L. Xu ${ }^{1 *}$, Z. Ali ${ }^{1,2 *}$, J.X. Yi ${ }^{1}$, X.L. He ${ }^{1}$, D.Y. Zhang ${ }^{1}$, G.H. Yu ${ }^{1}$, \\ A.A. Khan ${ }^{2}$ I.A. $\operatorname{Khan}^{3}$ and H.X. Ma ${ }^{1}$ \\ ${ }^{1}$ Institute of Agro-Biotechnology, Jiangsu Academy of Agricultural Sciences, \\ Nanjing, China \\ ${ }^{2}$ Departments of Plant Breeding and Genetics, \\ University of Agriculture, Faisalabad, Pakistan \\ ${ }^{3}$ Center for Agricultural Biochemistry and Biotechnology, \\ University of Agriculture, Faisalabad, Pakistan \\ *These authors contributed equally to this study. \\ Corresponding authors: J.X. Yi \\ E-mail: yij@jaas.ac.cn
}

Genet. Mol. Res. 10 (2): 1262-1276 (2011)

Received February 9, 2011

Accepted February 18, 2011

Published June 28, 2011

DOI 10.4238/vol10-2gmr1321

This study was sponsored by the National Science Foundation of China (\#30971798) and the Special Fund for Independent Innovation of Agricultural Science and Technology in Jiangsu (\#CX-10-433).

ABSTRACT. Salicornia spp is one of the most salt-tolerant vascular plants and is native to salt marshes and estuaries. We developed expressed sequence tag derived-simple sequence repeat (EST-SSR) markers for estimating genetic diversity and marker-assisted Salicornia breeding. Six polymorphic EST-SSRs of 40 detected 27 alleles, ranging from three to five alleles per locus. The average number of alleles per locus was 4.33 and 4.17, and the major allele frequency at locus DY529765 was high, being 0.859 and 0.857 in S. bigelovii and S. europea, respectively. Gene diversity, heterozygosity and polymorphism information content were highest at locus DY529950 and similar in 
these two species. Gene diversity increased with increase in the number of alleles that had a low major allele frequency at a locus. Six polymorphic loci effectively discriminated 46 taxa into three clusters via different analyses. Significant deviation of $F_{S T}$ from zero in three suggested populations for six loci indicated population differentiation and limited gene flow among them. A reduced median network established that taxon SB65 is primitive. SMART (simple modular architecture research tool) analysis of peptide sequences of six EST-SSRs showed that loci DY529765, DY529950 and EC906203 contained transmembrane, TLC, AgrB and NTR domains and might be involved in salinity stress tolerance. These EST-SSRs are a valuable resource for marker development and may be useful in marker-assisted Salicornia breeding.

Key words: Gene diversity; Gene flow; Allele frequency; Reduced median network; Salinity tolerance

\section{INTRODUCTION}

Salicornia, glasswort also known as sea asparagus, is a widespread hygrohalophytic cosmopolitan genus of succulent annual herbs of family Amaranthaceae. The genus is taxonomically described as a nightmare (Kadereit et al., 2007), native to salt marshes and estuaries, arguably, one of the most salt-tolerant vascular plants (Ayala and O'Leary, 1995). Its seeds have been reported to produce oil that is high in polyunsaturated fat and is comparable to soybean (Glenn et al., 1991, 1998) and safflower (Christiansen, 2008). After oil extraction, the remaining oilseed biomass can be used as a high-protein feed for livestock (Glenn et al., 1991).

Although there is an increasing interest in the production of glassworts, taxonomic treatment of tribe Salicornieae especially genus Salicornia is still not satisfactory due to various reasons. The tribe is characterized by a simple and similar morphology having highly reduced leaves and flowers. Morphological distinction is only possible in fresh state between flowering and fruiting (Ge'hu et al., 1979). Plants show high levels of phenotypic plasticity (Sagane et al., 2003) and they are mostly cleistogamous (Noble et al., 1992), although hybridization has been suggested as well (Lahondère, 2004). Several authors (e.g., Stace, 1997) favor a wider species concept within Salicornia, in which segregates or microspecies, rather than species are distinguished, others (e.g., Ge'hu and Ge'hu-Franck, 1992; Lahondère, 2004) prefer a more narrow species view. To date the genus Salicornia contains around 21 species (Anonymous, 2010).

Pickleweed, Salicornia bigelovii Torr., is an important species in the genus, which is commercially cultivated as a specialty vegetable for the U.S. and European fresh produce markets (OASE, 2010). It also has potential for production of oilseeds, forage, and biofuels (Glenn et al., 1991, 1999; Weber et al., 2007; Christiansen, 2008). S. bigelovii is an out-crossing plant; however, seed setting with self-pollination is possible. Therefore, it can be hybridized among lines and purified through selfing. This species slightly differs from that being harvested along Europe's shores (S. europea). Another species, S. europaea is treated in a broad sense but its aggregate is represented in Eurasia and North America by several diploid and tetraploid races. In China, most probably Chinese plants belong primarily or exclusively to the Eurasian continental race known as $S$. prostrata Pallas (Ill. Pl. 8. 1803). 
Salicornia plants tend to have phenotypic variation partly caused by environmental parameters like temperature, salinity, soil quality, and plant density (Boorman et al., 2001). The specific limits of the classification of Salicornia plants based on the morphological features, especially based on dried plant features, are obscure (Ball, 1964). Molecular markers provide an opportunity to prove relevance between genotype and phenotype in the plants. Several anonymous molecular markers, like restriction fragment length polymorphism (RFLP), random amplified polymorphic DNA (RAPD), amplified fragment length polymorphism (AFLP), simple sequence repeats (SSRs), etc., have been developed for studies focused on genetic diversity, population genetics and structure. In contrast to anonymous random DNA markers, functional markers derived from polymorphic sites within genes have been recently used to functionally characterize allelic variation in plants (Andersen and Lübberstedt, 2003; Lübberstedt et al., 2005; Asp et al., 2007).

The SSRs are among the most variable DNA sequences in the genome (Weber, 1990), due to mutations whose rate and type depend mainly on the number of repeat motifs (Wierdl et al., 1997). However, the mutation rates differ among loci and among alleles, and also between species (Ellegren, 2000). Previously SSRs have been isolated from genomic libraries utilizing anonymous DNA fragments but in more recent studies SSRs have been detected through computational methods in sequence databases generated from large-scale expressed sequence tags (ESTs) sequencing projects. About 1 to 5\% ESTs from different plant species have been found to contain SSRs suitable for marker development (Kantety et al., 2002). EST-SSR markers have been developed for a number of plant species, including rice (Temnykh et al., 2001), durum wheat (Eujayl et al., 2002), barley (Thiel et al., 2003), wheat (Peng and Lapitan, 2005), and cotton (Han et al., 2006). As EST-SSR markers are directly associated with an expressed gene, thus, completely linked with putative qualitative or quantitative trait locus alleles. Therefore, EST-SSR markers being superior, more informative and conserved than anonymous markers (Andersen and Lübberstedt, 2003), are useful as anchor markers for comparative mapping across species, comparative genomics, and evolutionary studies (Eujayl et al., 2002; Kantety et al., 2002; Thiel et al., 2003). However, EST-SSR's conserved nature may also limit their degree of polymorphism. Several studies showed transferability of SSR loci within a genus to be above 50\%, but poor across genera (Eujayl et al., 2002; Thiel et al., 2003).

The taxanomic treatment of Salicornia is not satisfactory especially in China where it is in need of revision (Zhu et al., 2003). Therefore, in the present studies, different taxa of genus Salicornia were collected at random from the foreshore of the Yellow Sea, China, and classified into two groups based on their morphometric resemblances to either $S$. bigelovii or $S$. europaea. A comprehensive EST collection in the NCBI database (http://www.ncbi.nlm.nih.gov/) from genera Salicornia and Suaeda was computationally exploited for SSR identification. These EST-SSRs were used to determine genetic diversity within and among various naturally growing Salicornia populations. This paper presents EST-SSR-based molecular variance in naturally growing two Salicornia populations along the Chinese coast. This paper also identifies functionally associated EST-SSRs for developing useful markers to assist Salicornia breeding.

\section{MATERIAL AND METHODS}

\section{Plant materials}

Fresh young fleshy stems of 100 morphological different taxa of genus Salicornia 
were collected at random from the foreshore of the Yellow Sea, China. The stems of each taxa were packed separately in polyethylene bags, immediately placed in insulated ice box and kept in this box during their logistic transfer to the laboratory for storage at $-70^{\circ} \mathrm{C}$ until their further processing. Genomic DNA of the 100 samples was extracted individually using CTAB method (Doyle and Doyle, 1987). Good-quality DNA was obtained from 46 taxa only, 32 resembling morphologically to S. bigelovii and 14 to $S$. europea.

\section{Design of EST-SSR primers}

In total 2280 ESTs, 1103 from genus Salicornia, and 1177 from its close relative genus Suaeda were downloaded on January 12, 2009 from NCBI (http://www.ncbi.nlm.nih. gov/). These ESTs were analyzed for $\geq 20$-bp SSRs, using the SSRHunter 1.3 software (http:// en.bio-soft.net/dna/SSRHunter.html). Forty ESTs of 2280 contained SSRs of size $\geq 20 \mathrm{bp}$ and more than six of core repeats. Forty EST-SSR sequences were analyzed for their phylogenetic relationship using the Clustalx2 software (http://www.ebi.ac.uk/Tools/clustalx2/index. $\mathrm{html})$. Forty EST-SSRs were used in the present studies and a set of 6 polymorphic ESTSSRs was finally selected to use for further analyses in the present studies. Forward and reverse primers were designed using the Primer Premier 5.0 software (http://www.premierbiosoft. com/primerdesign/index.html) keeping target polymerase chain reaction (PCR) product size between 100-300 bp.

\section{PCR and PAGE}

PCR was performed with a $20-\mu \mathrm{L}$ volume containing $12.8 \mu \mathrm{L} \mathrm{ddH}_{2} \mathrm{O}, 1 \mu \mathrm{L}$ genomic DNA (20 ng/ $\mu \mathrm{L}), 0.4 \mu \mathrm{L}$ of each primer $(10 \mu \mathrm{M}), 2 \mu \mathrm{L}$ rTaq buffer (10X), $1.6 \mu \mathrm{L} \mathrm{MgCl}_{2}(25$ $\mathrm{mM}), 1.6 \mu \mathrm{L}$ dNTPs $(10 \mathrm{mM})$, and $0.2 \mu \mathrm{L}$ rTaq DNA polymerase $(5 \mathrm{U} / \mu \mathrm{L})$ (Takara Bio Inc; Shiga, Japan; http://www.takara-bio.com/). PCR was conducted in a thermo-cycler (LabCycler, SensoQuest Biomedizinische Elektronik, GmbH., Göttingen, Germany) set with initial denaturation temperature of $94^{\circ} \mathrm{C}$ for $3 \mathrm{~min}, 35$ cycles of denaturation at $94^{\circ} \mathrm{C}$ for $30 \mathrm{~s}$, annealing at $50-60^{\circ} \mathrm{C}$ for $30 \mathrm{~s}$ and extension at $72^{\circ} \mathrm{C}$ for $30 \mathrm{~s}$ followed by a final extension at $72^{\circ} \mathrm{C}$ for 3 min. PCR products were separated on $12 \%$ denaturing polyacrylamide gels followed by silver staining to detect and analyze the PCR products according to Bassam et al. (1991) with slight modifications ( $12 \%$ acetic acid, $0.2 \%$ silver nitrate, $6 \%$ sodium bicarbonate).

\section{Statistical data analysis}

Gene diversity, heterozygosity, polymorphism information content (PIC), and allele frequencies were calculated following functions explained in Liu and Muse (2005) and PowerMarker V3.0 Manual using the PowerMarker V3.0 software (see URL; http://www. powermarker.net for Manual and software). Effective loci discrimination was determined through principal component analysis (PCA) using PROC PRINCOMP in the SAS software. Inter-and intra-population structure depicting gene flow was constructed using the Structure V2.3.1 software (http://pritch.bsd.uchicago.edu/structure.html) according to Pritchard et al., (2000). Reduced median network was constructed using the Network 4.5.1.6. software (www. fluxus-engineering.com/network_terms.htm). 


\section{RESULTS}

\section{Polymorphism, allele distribution and genetic diversity within and among populations}

Phylogenetic tree of 40 EST-SSRs was subdivided into three groups (Figure 1). All EST-SSRs in group I and few in group III appeared to be of high similarity. EST-SSRs in group II were more diverse. Of 40 six EST-SSRs, one from each group I and group III, and four from group II, were polymorphic and thus used to genotype 32 S. bigelovii and 14 S. europea taxa (Table 1). Rest of diverse EST-SSRs from groups II and III did not amplify or become polymorphic within target size. All six polymorphic loci detected 27 alleles in total. Average allele numbers per locus within the population were comparable between two populations, 4.33 and 4.17 in S. bigelovii and S. europea, respectively (minimum $=3$, maximum $=5$ alleles per locus in each population; Table 2). Allele E was not detected at respective loci of BE240888, and EC906203 and EC906222 in S. bigelovii and S. europea. Frequency of major allele C (145 bp) at locus DY529765 was significantly $(\mathrm{P}<0.05)$ high among all loci, 0.859 and 0.857 in S. bigelovii and S. europea, respectively. Conversely, major alleles A (160 bp) in S. bigelovii and B (165 bp) in S. europea at DY529950 were significantly less frequent among the six loci. Null alleles were observed at locus DY529903 in both populations and at EC906222 in S. bigelovii alone. All taxa from both populations deviated significantly from Hardy-Weinberg equilibrium (HWE) at all loci except at DY529765 in S. europea (data not shown).

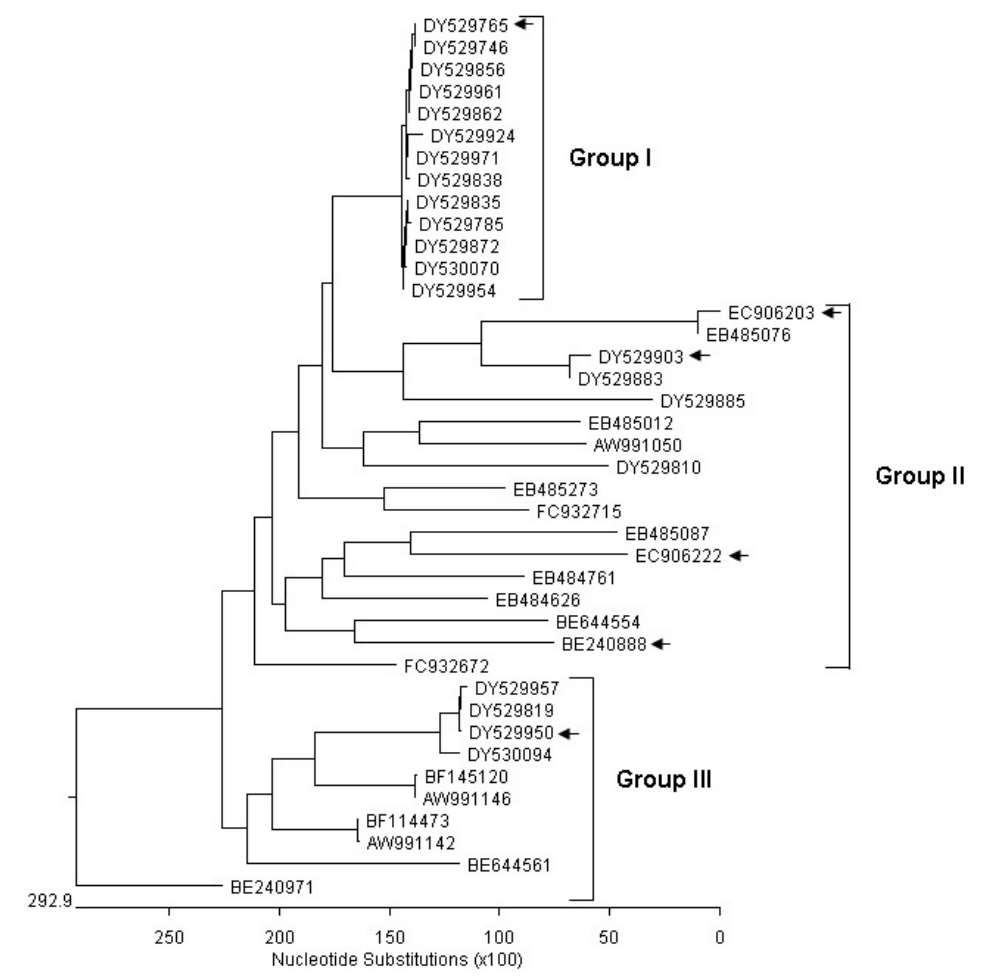

Figure 1. Phylogenetic tree of 40 EST-SSRs. Polymorphic EST-SSRs are pointed with arrows 


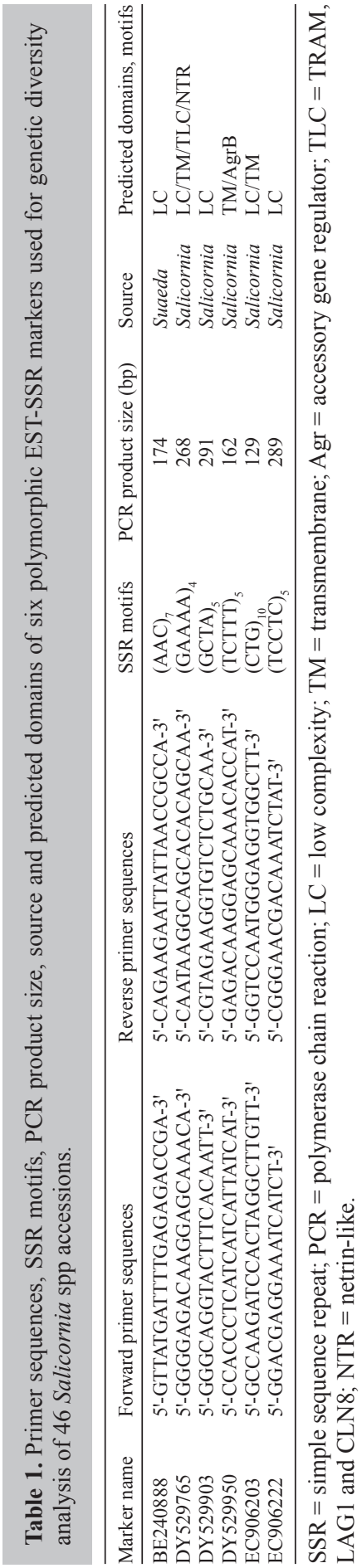


Table 2. Allele frequency distribution within and between Salicornia bigelovii and S. europea.

\begin{tabular}{|c|c|c|c|c|}
\hline Locus & Allele name & Allele size (bp) & S. bigelovii & S. europea \\
\hline \multirow[t]{5}{*}{ BE240888 } & A & 135 & 0.047 & 0.071 \\
\hline & $\mathrm{B}$ & 141 & 0.156 & 0.214 \\
\hline & $\mathrm{C}$ & 147 & $0.469^{a}$ & $0.429^{a}$ \\
\hline & $\mathrm{D}$ & 150 & 0.328 & 0.214 \\
\hline & $\mathrm{E}$ & 156 & - & 0.071 \\
\hline \multirow[t]{4}{*}{ DY529765 } & A & 135 & 0.047 & 0.036 \\
\hline & B & 140 & 0.047 & 0.071 \\
\hline & $\mathrm{C}$ & 145 & $0.859^{a}$ & $0.857^{a}$ \\
\hline & $\mathrm{D}$ & 160 & 0.047 & 0.036 \\
\hline \multirow[t]{3}{*}{ DY529903 } & A & 292 & 0.313 & 0.357 \\
\hline & B & 304 & $0.625^{a}$ & $0.429^{a}$ \\
\hline & $\mathrm{C}$ & Null & 0.063 & 0.214 \\
\hline \multirow[t]{5}{*}{ DY529950 } & A & 160 & $0.281^{a}$ & 0.071 \\
\hline & B & 165 & 0.266 & $0.250^{a}$ \\
\hline & $\mathrm{C}$ & 170 & 0.094 & 0.214 \\
\hline & $\mathrm{D}$ & 180 & 0.094 & 0.214 \\
\hline & $\mathrm{E}$ & 185 & 0.266 & $0.250^{a}$ \\
\hline \multirow[t]{5}{*}{ EC906203 } & $\mathrm{A}$ & 113 & 0.063 & 0.107 \\
\hline & B & 119 & 0.063 & 0.071 \\
\hline & $\mathrm{C}$ & 122 & 0.297 & $0.536^{a}$ \\
\hline & $\mathrm{D}$ & 131 & $0.547^{a}$ & 0.286 \\
\hline & $\mathrm{E}$ & 152 & 0.031 & - \\
\hline \multirow[t]{8}{*}{ EC906222 } & A & 170 & 0.109 & 0.143 \\
\hline & B & 180 & 0.344 & 0.321 \\
\hline & $\mathrm{C}$ & 185 & 0.031 & 0.071 \\
\hline & $\mathrm{D}$ & 195 & $0.453^{a}$ & $0.464^{a}$ \\
\hline & $\mathrm{E}$ & Null & 0.063 & - \\
\hline & Average allele numbers per locus & & 4.333 & 4.167 \\
\hline & Major allele's average frequency & & 0.539 & 0.494 \\
\hline & SEM & & 0.222 & 0.200 \\
\hline
\end{tabular}

${ }^{a}$ major allele $=$ having highest frequency at each locus within population; SEM = standard error of the mean.

Gene diversity, heterozygosity and PIC remained highest at locus DY529950 (Table 3). Ranges of respective gene diversity in S. bigelovii and S. europea were $0.255-0.762$ and $0.258-0.778$. Heterozygosity and PIC in respective aforementioned populations ranged between zero and 0.906 and 0.929 , and $0.245-0.722$ and $0.246-0.741$, respectively. Four loci BE240888, DY529903, EC906203, and EC906222 were statistically almost similar (P<0.05) in their depiction of gene diversity and PIC. Significant $(\mathrm{P}<0.05)$ positive association was observed between gene diversity and PIC while major allele frequency showed strong negative association with gene diversity and PIC (Figure 2).

\begin{tabular}{|c|c|c|c|c|c|c|}
\hline \multirow[t]{2}{*}{ Loci } & \multicolumn{3}{|c|}{ S. bigelovii } & \multicolumn{3}{|c|}{ S. europea } \\
\hline & Gene diversity & Heterozygosity & PIC & Gene diversity & Heterozygosity & PIC \\
\hline BE240888 & 0.646 & 0.094 & 0.581 & 0.714 & 0.000 & 0.671 \\
\hline DY529765 & 0.255 & 0.188 & 0.245 & 0.258 & 0.214 & 0.246 \\
\hline DY529903 & 0.508 & 0.000 & 0.428 & 0.643 & 0.000 & 0.567 \\
\hline DY529950 & 0.762 & 0.719 & 0.722 & 0.778 & 0.929 & 0.741 \\
\hline EC906203 & 0.604 & 0.313 & 0.544 & 0.615 & 0.071 & 0.556 \\
\hline ЕС906222 & 0.660 & 0.906 & 0.600 & 0.656 & 0.929 & 0.595 \\
\hline Average & 0.572 & 0.370 & 0.520 & 0.611 & 0.357 & 0.563 \\
\hline SEM & 0.176 & 0.363 & 0.165 & 0.182 & 0.450 & 0.170 \\
\hline
\end{tabular}

$\mathrm{SEM}=$ standard error of the mean. 


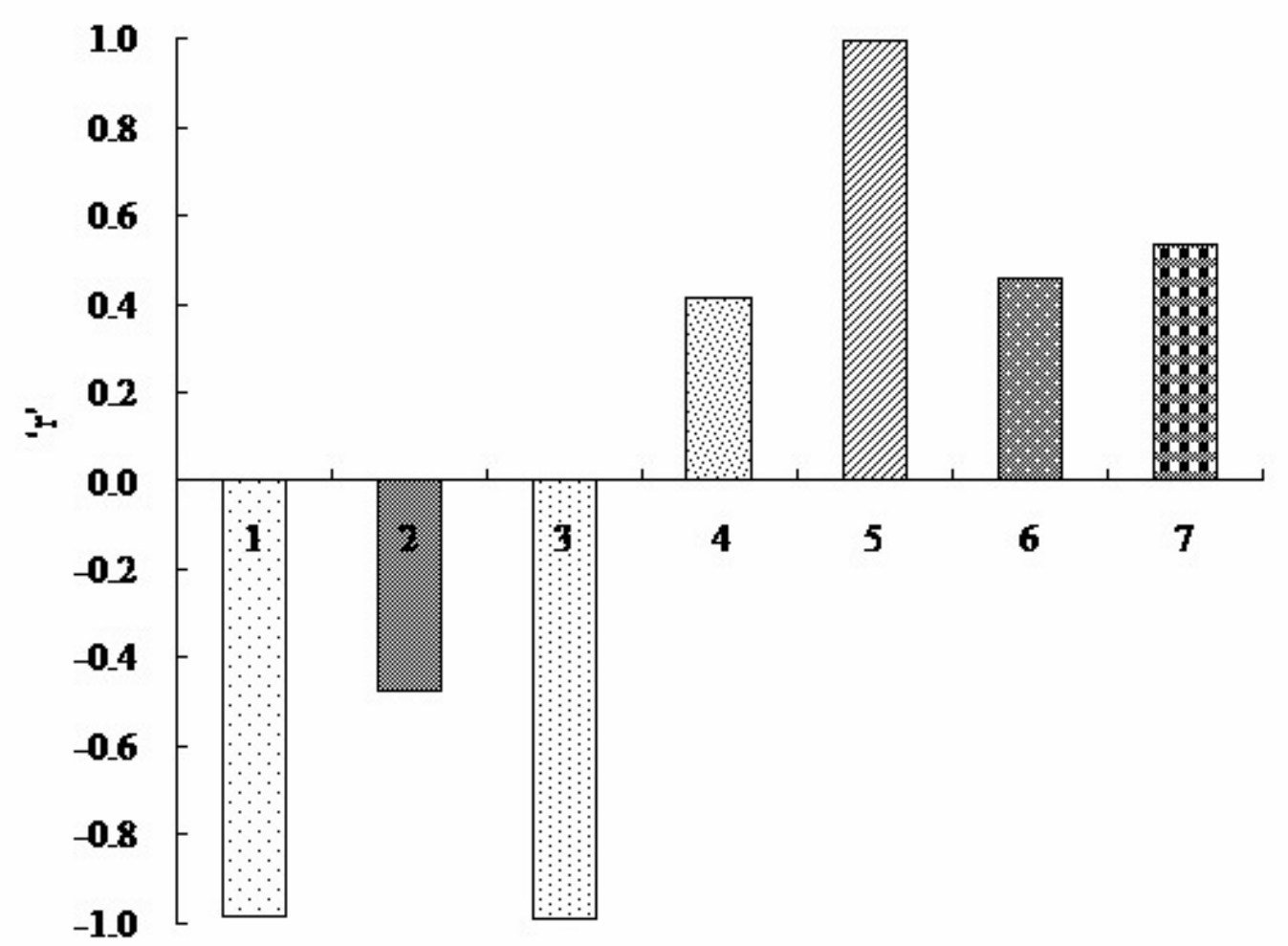

Figure 2. Correlation coefficients ' $r$ ' between selective parameters. $1=$ Major allele frequency (MAF) $v s$ genetic diversity (GD); 2 = MAF vs heterozygosity (HET); 3 = MAF $v s$ polymorphism information content (PIC); 4 = GD vs HET; 5 = GD vs PIC; $6=$ HET vs PIC; 7 = number of alleles vs GD.

\section{Gene flowing between populations}

Six polymorphic loci effectively discriminated predefined two populations, based on morphological classification, into three clusters via PCA (Figure 3). Considerable overlaps between $S$. bigelovii and $S$. europea populations were evident. The majority of taxa from S. europea grouped into clusters II and III, while cluster I contained only two taxa from S. europea. Phylogenetic analysis and UPGMA tree view constructed via Ni's estimates also substantiated the results of PCA (data not shown).

The pairwise global estimate of $F_{S T}$ indicated significant differentiation between populations after correction for multiple comparisons, with $F_{S T}$ values ranging from 0.189 to 0.481 . The Bayesian clustering procedure detected the maximum likelihood for a model of three genetically distinct populations $(K=3, \ln P(D)=-438.3)$ via STRUCTURE 2.3 basic algorithm described by Pritchard et al. (2000). For K $>3$, the clustering process failed to calculate a homogeneous posterior probability of the data between each iteration (Figure 4A). The STRUCTURE algorithm showed that a parti- 
tioning of the genetic variation into three clusters was most probable when independent and correlated allele frequencies were applied (Figure 4B). A large proportion of the taxa have a genetic signature typical for one specific cluster. However, some taxa have a divided membership between two and three clusters.

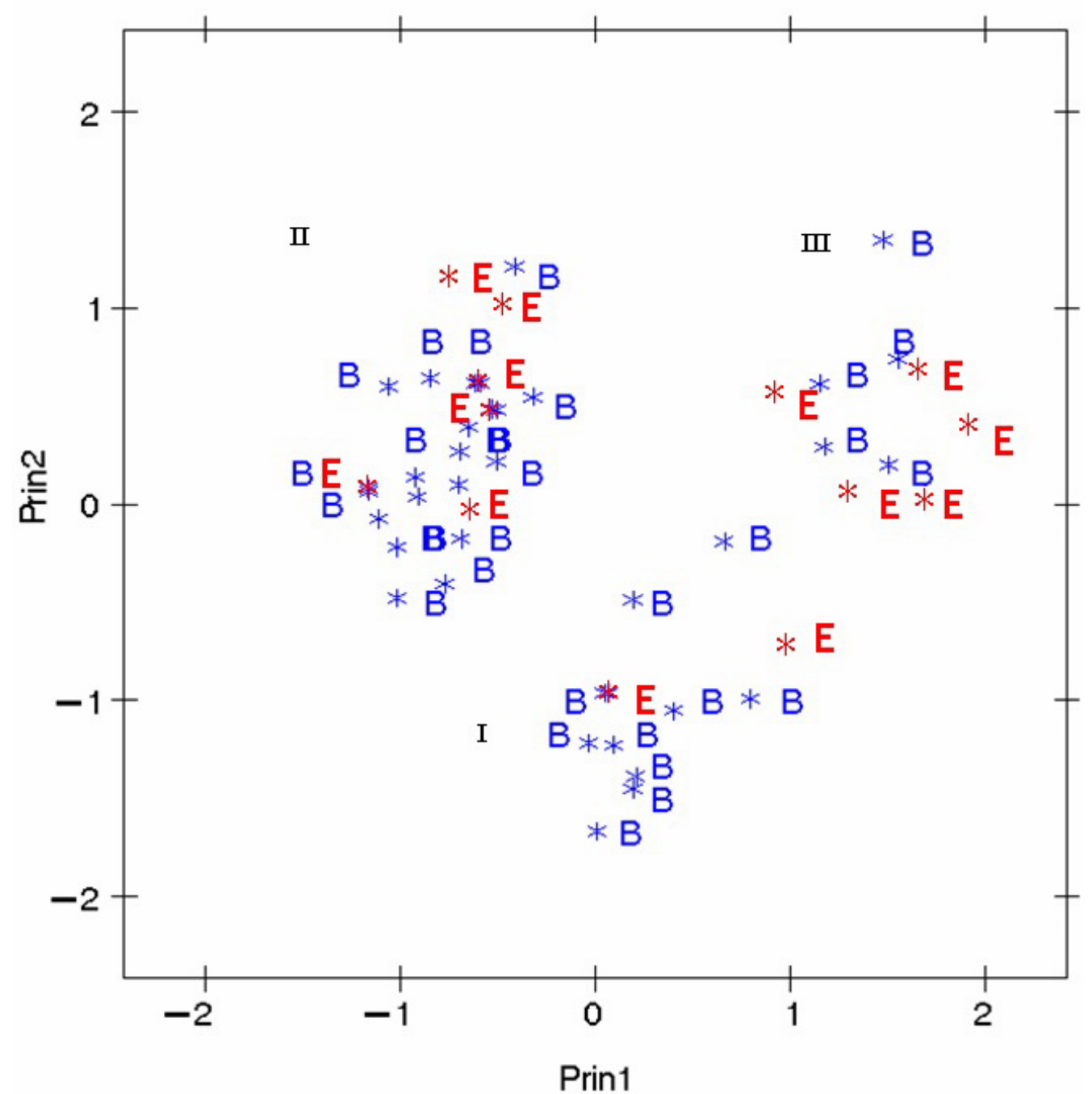

Figure 3. Effective loci discriminating predefined two populations into three clusters revealed by principal component analysis. 'B' represents Salicornia bigelovii and 'E' S. europea.

\section{Detection of mutation in allele and taxa phylogenies via network analysis}

Twenty-three of 27 alleles appeared in reduced median (RM) network analysis (Figure 5A). BE8885 appeared as consensus and/or reference allele, the rest of alleles showed deviations from the reference allele. DY9502 and DY9505 shared high similarity of nucleotide 
sequence and high similarity was shared between EC2224 and DY7653 as well. RM network analysis of 46 taxa exhibited parallelism in 3 taxa only while 43 taxa were apparent in the network (Figure 5B). Figure 5B depicts SB65 as consensus or reference taxon. Descendants of node SB69 are grouped into two clades. One clade is descended from SE61 while the second clade is from node SB68. Clade from node SE61 includes $\sim 50 \%$ of taxa from morphologically categorized S. europea while clade from node SB68 includes only one taxon SE10 from $S$. europea.

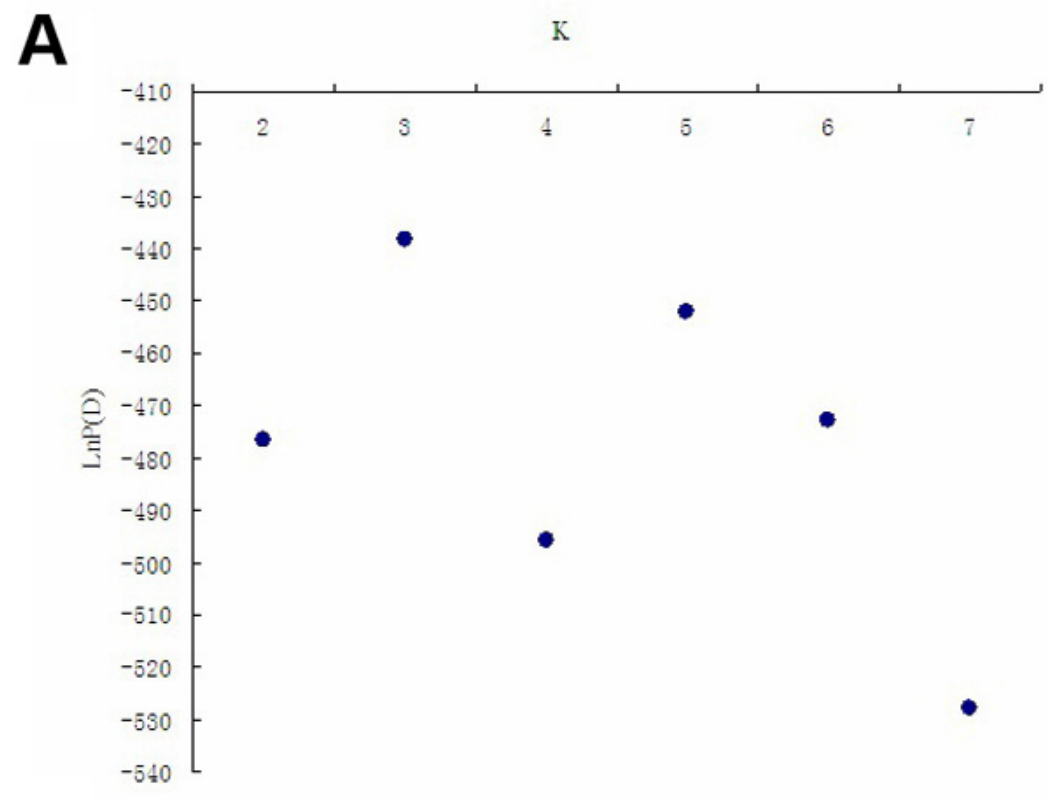

\section{B}

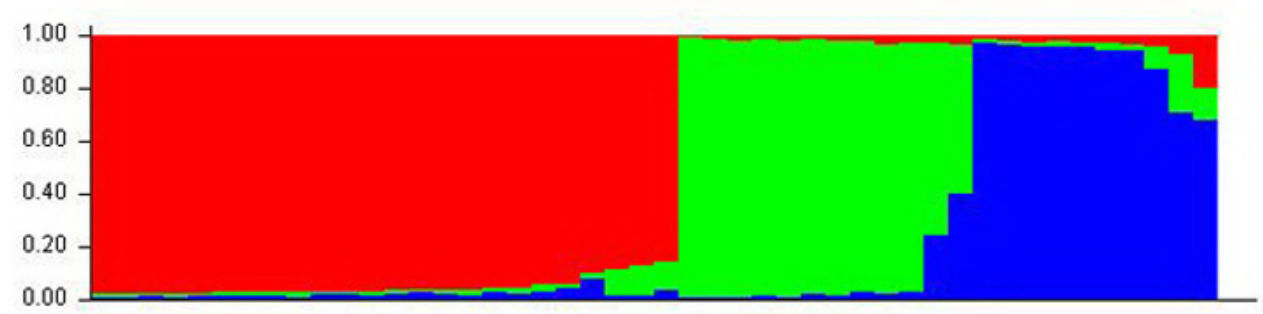

Figure 4. Structure of inter- and intra-populations. A. Estimated logarithms of data $[\mathrm{LnP}(\mathrm{D})]$ against the number of populations tested (K). B. Estimated population structure inferred from the whole Salicornia taxa for $\mathrm{K}=3$. Each taxon is represented by a thin vertical line, which is partitioned into K colored segments representing the taxon's estimated membership fraction in K clusters. 

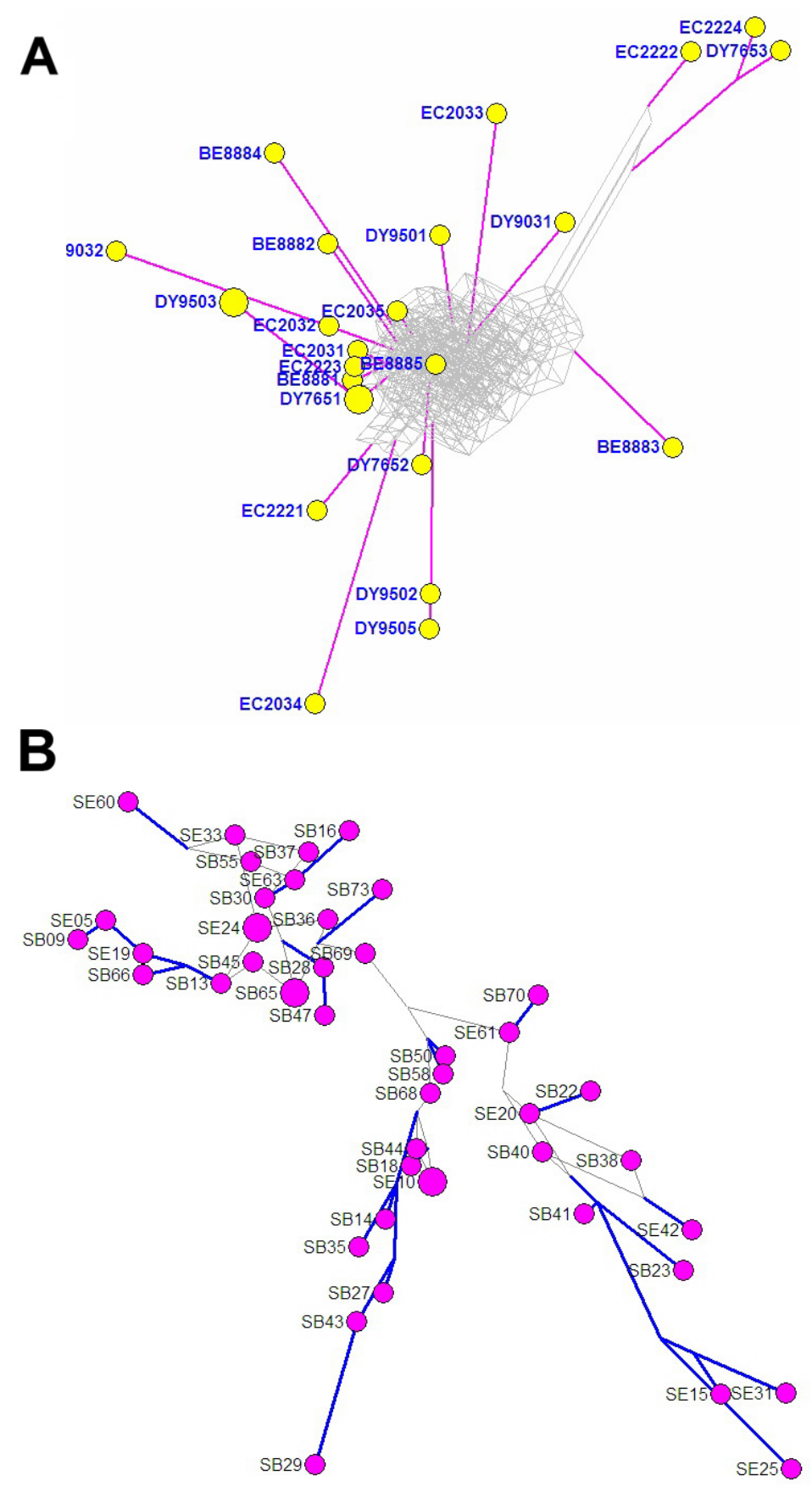

Figure 5. Reduced median network analysis. A. Networking among 27 alleles; names contain the first two letters and the last 3 digits from the respective EST-SSRs while the last digit of the name showed the respective allele number at the locus. B. Networking among 46 taxa, SB stands for Salicornia bigelovii and SE for S. europea. 


\section{DISCUSSION}

\section{Genetic diversity within and among populations}

EST-SSR marker system is increasingly being used for diversity analyses in breeding and natural populations or genbank materials due to their power of functional diversity examination (Asp et al., 2007; Salem et al., 2010) and inexpensive development costs (Varshney et al., 2005). Computational analysis depicted that only 40 (1.75\%) ESTs found in two genera, Salicornia and Suaeda, contained SSRs of size $\geq 20$ bp and six (15\% of 40) EST-SSRs were polymorphic and thus used for further analyses in the present study (Figure 1). Of six ESTSSRs, five were from Salicornia and one from Suaeda (Table 1). High level of polymorphism associated with SSRs is to be expected because of the unique mechanism responsible for generating SSR allelic diversity by replication slippage (Varshney et al., 2005). These polymorphic markers were able to discriminate among various taxa of Salicornia.

Gene diversity, heterozygosity and PIC are high at locus DY529950 but its major allele frequency is less and vice versa at locus DY529765 (Tables 2 and 3). Former locus has more number of alleles (5) compared to the latter ones (4 alleles). A positive significant association between number of alleles and gene diversity has been previously reported, and the use of number of alleles to evaluate the genetic diversity has been suggested (Salem et al., 2010). The correlation between gene diversity and the number of alleles at six polymorphic loci is moderate $(r=0.533)$ and less than $r=0.741$ reported earlier in barley (Salem et al., 2010). Results at two aforementioned loci agree with the suggestion of Salem et al. (2010) but our cumulative data at six loci do not support this suggestion. However, large number of alleles with low major allele frequency at a locus produced high gene diversity and PIC values, and vice versa. Therefore, the use of the number of alleles together with their major allele frequency at a particular locus is suggested in order to evaluate the genetic diversity.

Average gene diversity, heterozygosity and PIC within each population were high and also remained comparable between two populations morphologically categorized (Table 3). Large number of alleles and high gene diversity/PIC confirm broader genetic base of two populations. This might be due to out-crossing nature of the plants and equal distribution of salt-tolerant genes among the two populations. It is quite possible that these two populations might have common ancestors and share many genes in common. Average PIC values of 0.520 and 0.563 in $S$. bigelovii and S. europea, respectively, confirmed that EST-SSR markers are highly informative in the two populations. Strong association between gene diversity and PIC indicated that gene diversity is essentially the same as PIC (Botstein et al., 1980; Anderson et al., 1993).

The genus Salicornia is native to salt marshes and estuaries, arguably, one of the most salt-tolerant vascular plants (Ayala and O'Leary, 1995). Simple modular architecture research tool (SMART) analysis of amino acid sequences coded by nucleotide sequence of ESTs showed involvement of domains responsible for salt tolerance. Three Salicornia loci DY529765, DY529950 and EC906203 contained transmembrane domains, DY529765's TLC domain and DY529950's AgrB domain have transport activities and may be involved in abiotic stress particularly salinity stress tolerance. Hence, these EST-SSRs are valuable resource for marker development and may be useful in marker assisted Salicornia breeding aimed at improving salt tolerance. As allele C at locus DY529765, which contains transmembrane, TLC and NTR domains, is most frequent among salt tolerant 46 taxa collected from the Yel- 
low Sea coast, thus it may be used for development of an important salt-tolerant marker. However, further investigation to explore its expression and tolerance mechanisms is needed.

\section{Gene flowing between populations}

Phenotypic variation in Salicornia plants might be caused by environmental parameters like temperature, salinity, soil quality, and plants density (Boorman et al., 2001). Morphological features were suggested to be obscure for classification of Salicornia plants (Ball, 1964). Molecular discrimination of two morphological distinct populations into three distinct clusters via PCA, phylogenetic analysis and UPGMA tree view, and considerable overlaps between S. bigelovii and S. europea populations evidenced the involvement of common genes (Figure 3). Out-crossing nature of the plant, anthesis over a period of 30-60 days (Zerai et al., 2010) and co-existence of taxa within the same locality might have promoted the gene flow between the two populations. There were several deviations within each population due to this gene flow. The gene flow also resulted in evolution of a third molecular group whose members morphologically resemble the two populations. Some of the taxa appeared to be admixture of two populations. Previous studies reported deviation between molecular- and morphologicalbased classification of Salicornia plants, e.g., morphologically distinct two species of Salicornia in Japan consisted of five molecular groups (Sagane et al., 2003).

Previously, genetic differentiation between the six homogeneous clusters of spotted gum species obtained from STRUCTURE mirrored geographically separated sampling localities (Ochieng et al., 2010). In the present study, significant deviation of $F_{S T}$ from zero over three populations and six loci indicated population differentiation and limited gene flow among the three suggested populations. Specific typical genetic signature of most of the members of each cluster supports division of 46 taxa into three distinct populations (Figure 4B). However, divided membership of some taxa between two and/or three clusters substantiated the gene flow among the taxa and it appeared to be more appropriate that these three clusters/ populations are microspecies rather than distinct species.

RM network analysis showed three different clades/branches (Figure 5B). Major clade containing SB65 as reference taxon also contains SB69, which may be evolved from SB65. Other two clades appeared to be descendent from SB69. SE61 originating from SB69 descends 50\% S. europea and 50\% S. bigelovii while SB68 descends the majority of S. bigelovii types. SE61 clade showed high gene diversity and PIC compared to the rest of two clades (data not shown) and thus have more broader genetic base. Distances of various taxa from the respective reference taxon showed the magnitude of mutations and deviations of respective taxon from the reference or consensus taxon (see for explanation, Bandelt et al., 1995). This analysis suggested the existence of three different clades or microspecies within $S$. bigelovii, as the majority of taxa resembled with this species found at the coast of the Yellow Sea.

\section{CONCLUSIONS}

The present study highlights the discrimination power of EST-SSR marker system to analyze functional diversity in breeding and natural populations or genbank materials for its exploitation in crop improvement as well as ex situ conservation strategies of plant genetic resources. These EST-SSRs that have major domains involved in salinity tolerance are a useful 
resource for salt-tolerant marker development. Three Salicornia loci, DY529765, DY529950 and EC906203, contained transmembrane, TLC, AgrB, and NTR domains, and might be involved in salinity stress tolerance and are thus potentially useful in marker-assisted Salicornia breeding. Gene diversity increased with an increase in number of alleles having low major allele frequency at a locus and vice versa. Molecular data explained the high gene diversity among the 46 Salicornia taxa; however, it did not support the morphological classification of 46 Salicornia taxa found at Chinese coast of the Yellow Sea into two populations but rather explained the existence of the three populations.

\section{ACKNOWLEDGMENTS}

Z. Ali appreciates financial assistance from Jiangsu and Punjab sister provinces of China and Pakistan for his visit at Jiangsu Academy of Agricultural Sciences, Nanjing, Jiangsu, P.R. China.

\section{REFERENCES}

Andersen JR and Lübberstedt T (2003). Functional markers in plants. Trends Plant Sci. 8: 554-560.

Anderson JA, Churchill GA, Autrique JE, Tanksley SD, et al. (1993). Optimizing parental selection for genetic linkage maps. Genome 36: 181-186.

Anonymous (2010). Botenica systematica. Available at [http://www.homolaicus.com/scienza/erbario/utility/botanica sistematica/hypertext/1726.htm]. Accessed April 2010.

Asp T, Frei UK, Didion T, Nielsen KK, et al. (2007). Frequency, type, and distribution of EST-SSRs from three genotypes of Lolium perenne, and their conservation across orthologous sequences of Festuca arundinacea, Brachypodium distachyon, and Oryza sativa. BMC Plant Biol. 7: 36.

Ayala F and O'Leary JW (1995). Growth and physiology of Salicornia bigelovii Torr. at suboptimal salinity. Int. J. Plant. Sci. 156: 197-205.

Ball PW (1964). Salicornia. In: Flora Europaea (Tutin TG, Heywood VH, Burges NA and Valentine DH, eds.). Cambridge University Press, London, 101-102.

Bandelt HJ, Forster P, Sykes BC and Richards MB (1995). Mitochondrial portraits of human populations using median networks. Genetics 141: 743-753.

Bassam BJ, Caetano-Anollés G and Gresshoff PM (1991). Fast and sensitive silver staining of DNA in polyacrylamide gels. Anal. Biochem. 196: 80-83.

Boorman LA, Hazelden J and Boorman M (2001). The effect of rates of sedimentation and tidal submersion regimes on the growth of salt marsh plants. Continent. Shelf Res. 21: 2155-2165.

Botstein D, White RL, Skolnick M and Davis RW (1980). Construction of a genetic linkage map in man using restriction fragment length polymorphisms. Am. J. Hum. Genet. 32: 314-331.

Christiansen R (2008). Sea asparagus can be oilseed feedstock for biodiesel. Biomass Magazine, August, 2008. Available at [http://www.biomassmagazine.com/article.jsp?articleid=1864]. Accessed May 26, 2010.

Doyle JJ and Doyle JL (1987). A rapid DNA isolation procedure from small quantities of fresh leaf tissue. Phytochem. Bull. 19: 11-15.

Ellegren H (2000). Microsatellite mutations in the germline: implications for evolutionary inference. Trends Genet. 16: 551-558.

Eujayl I, Sorrells ME, Baum M, Wolters P, et al. (2002). Isolation of EST-derived microsatellite markers for genotyping the A and B genomes of wheat. Theor. Appl. Genet. 104: 399-407.

Ge'hu JM and Ge'hu-Franck J (1992). Les Salicornes Annuelles du Nord-ouest de la France et leur Phytoecologie. In: Colloques Phytosociologiques. Cramer, Berlin Stuttgart, 25-40.

Ge'hu JM, Caron B and Franck J (1979). Essai de cle pour les salicornes annuelles presentes sur les cotes du projet de carte floristique IFFP. Doc. Flor 2: 17-24.

Glenn EP, O'Leary JW, Watson MC, Thompson TL, et al. (1991). Salicornia bigelovii Torr.: an oilseed halophyte for seawater irrigation. Science 251: 1065-1067.

Glenn EP, Brown J and O'Leary J (1998). Irrigating crops with seawater. Sci. Am. 279: 56-61. 
Glenn EP, Brown JJ and Blumwald E (1999). Salt tolerance and crop potential of halophytes. Crit. Ver. Plant Sci. 18: 227-255.

Han Z, Wang C, Song X, Guo W, et al. (2006). Characteristics, development and mapping of Gossypium hirsutum derived EST-SSRs in allotetraploid cotton. Theor. Appl. Genet. 112: 430-439.

Kadereit G, Ball P, Beer S, Mucina L, et al. (2007). A taxonomic nightmare comes true: phylogeny and biogeography of glassworts (Salicornia L., Chenopodiaceae). Taxon 56: 1143-1170.

Kantety RV, La Rota M, Matthews DE and Sorrells ME (2002). Data mining for simple sequence repeats in expressed sequence tags from barley, maize, rice, sorghum and wheat. Plant Mol. Biol. 48: 501-510.

Lahondère C (2004). Les Salicornes s.1. (Salicornia L., Sarcocornia A. J. Scott et Arthrocnemum Moq.) sur les Côtes Françaises. Socité Botanique du Centre-Oest, Saint-Sulpice-de-Royan.

Liu K and Muse SV (2005). PowerMarker: an integrated analysis environment for genetic marker analysis. Bioinformatics 21: 2128-2129.

Lübberstedt T, Zein I, Andersen JR, Wenzel G, et al. (2005). Development and application of functional markers in maize. Euphytica 146: 101-108.

Noble SM, Davy AJ and Oliver RP (1992). Ribosomal DNA variation and population differentiation in Salicornia L. New Phytol. 122: 553-565.

OASE Foundation (2010). Biosaline Agriculture. Amsterdam, The Netherlands. Available at [http://www.oasefoundation. eu/project_sub/163]. Accessed April 2010.

Ochieng JW, Shepherd M, Baverstock PR, Nikles G, et al. (2010). Two sympatric spotted gum species are molecularly homogeneous. Conserv. Genet. 11: 45-56.

Peng JH and Lapitan NL (2005). Characterization of EST-derived microsatellites in the wheat genome and development of eSSR markers. Funct. Integr. Genomics 5: 80-96.

Pritchard JK, Stephens M and Donnelly P (2000). Inference of population structure using multilocus genotype data. Genetics 155: 945-959.

Sagane Y, Sato K and Momonoki YS (2003). Identification of Salicornia populations: comparison between morphological characterization and RAPD fingerprinting. Plant Prod. Sci. 6: 287-294.

Salem KFM, Varshney RK, Röder MS and Börner A (2010). EST-SSR based estimates on functional genetic variation in a barley (Hordeum vulgare L.). collection from Egypt. Genet. Res. Crop Evol. 57: 515-521.

Stace CA (1997). New Flora of the British Isles. Cambridge University Press, Cambridge.

Temnykh S, Temnykh S, Lukashova A, Lipovich L, et al. (2001). Computational and experimental analysis of microsatellites in rice (Oryza sativa L.): frequency, length variation, transposon associations, and genetic marker potential. Genome Res. 11: 1441-1452.

Thiel T, Michalek W, Varshney RK and Graner A (2003). Exploiting EST databases for the development and characterization of gene-derived SSR-markers in barley (Hordeum vulgare L.). Theor. Appl. Genet. 106: 411-422.

Varshney RK, Graner A and Sorrells ME (2005). Genic microsatellite markers in plants: features and applications. Trends Biotechnol. 23: 48-55.

Weber DJ, Ansari R, Gul B and Khan MA (2007). Potential of halophytes as sources of edible oil. J. Arid Environ. 68: 315-321.

Weber JL (1990). Informativeness of human (dC-dA)n.(dG-dT)n polymorphisms. Genomics 7: 524-530.

Wierdl M, Dominska M and Petes TD (1997). Microsatellite instability in yeast: dependence on the length of the microsatellite. Genetics 146: 769-779.

Zerai DB, Glenn EP, Chatervedi R, Lu Z, et al. (2010). Potential for the improvement of Salicornia bigelovii through selective breeding. Ecol. Eng. 36: 730-739.

Zhu G, Mosyakin SL and Clemants SE (2003). Chenopodiaceae Ventenat. Flora China 5: 351-414. 